\title{
BARROCO Y TRANSHISTORIEDAD EN LATINOAMÉRICA Y CHILE
}

\author{
Luz Ángela Martínez \\ Universidad de Chile \\ luzmartine@gmail.com
}

\section{RESUMEN/ABSTRACT}

\begin{abstract}
Este trabajo aborda la transhistoriedad del Barroco latinoamericano y chileno, vinculándolo con los distintos estadios de globalización experimentados por la cultura latinoamericana, desde el siglo XVI hasta hoy. Se centra en el caso chileno, donde identifica la matriz poética e histórica del Barroco de Frontera, recorriendo desde La Araucana hasta poéticas neobarrocas actuales.
\end{abstract}

PALABRAS CLAVE: neobarroco, transhistoriedad, globalización, poéticas neobarrocas, Chile.

This work deals with the transhistority of the latin american and chilean baroque, linking it with different stages of globalization experienced by the latin american culture since the $X V I$ century until now. The articule focuses in the chilean case, identifying the poetic and historical structure of the Border Baroque, going over from La Araucana up to contemporary neobaroque poetics.

KEYWORDS: neobaroque, transhistority, globalization, neobaroque poetics, Chile.

Cualquier intento de abordar el actual momento neobarroco en Latinoamérica y en Chile particularmente requiere adelantar algunos supuestos básicos sobre lo que se entiende por "Barroco", advirtiendo de paso que tales supuestos no son otra cosa que la adopción de un punto de vista. Lo primero a decir: aquí "Barroco" señala, refiere y convoca una productividad escritural, representacional, teórica y poética asociada a una serie de problemáticas culturales y espirituales transhistóricas, reconocidas, reunidas, -dispersadas también- en Latinoamérica bajo ese mismo rótulo desde el siglo XVI hasta 
hoy. Lo segundo, el término transhistoriedad no supone ningún tipo de categoría metafísica y menos a-histórica ${ }^{1}$. No refiere, por lo tanto, ningún concepto a priori que pueda ser pensado fuera del desarrollo histórico de las artes, de la literatura, el ensayo crítico y el pensamiento latinoamericanos. Por el contrario, la atracción del término a este contexto busca relevar el vínculo entre escritura, arte (sus representaciones, prácticas, cruces, sus múltiples condiciones de visibilidad) y circunstancia histórica ${ }^{2}$, de la cual, en definitiva, parte toda creación y recreación imaginaria; toda creación y reformulación teórica; todo asunto estético. En este ensayo, el término transhistoriedad orienta, principalmente, el fenómeno en virtud del cual el Barroco se presenta como expresión y legibilidad de distintas épocas históricas y estadios de globalización en Hispanoamérica y luego en Latinoamérica, de tal manera que no aludimos a lo mismo si es que hablamos del Barroco de Indias (siglo XVI y la primera globalización); del Barroco americano (primera mitad del siglo XX); o del Neobarroco (siglo XX y XXI; segundo y tercer estadio globalizador experimentados por nuestra cultura). Por lo tanto, no referimos los mismos tejidos sociales, ni las mismas tecnologías de configuración del signo; tampoco confundimos los mapas culturales que cada uno de esos rótulos convoca. Sin embargo, la distinción clara de cada una de las apariciones del Barroco en América exige reconocer al mismo tiempo un doble trabajo de escritura y lenguaje, un sustrato poético-histórico que comunica tres momentos distantes y específicos de nuestra cultura, que es, en definitiva, lo que configura y confirma la transhistoriedad del Barroco latinoamericano. En este sentido, la datación del sustrato es lo que señala al Barroco como un fenómeno transhistórico, cuya duración y permanencia alcanza la condición de memoria en Latinoamérica: memoria poética.

La productividad a la que me refiero (más tarde reconocida como "Barroco") tiene relación directa con uno de los más grandes sucesos de escritura ${ }^{3}$ de que tiene noticia la humanidad. Se trata de aquellas Letras en la que, por partes,

1 La transhistoriedad a la que me refiero marca una distancia irreducible de la idea del Barroco como "constante del espíritu" (Carpentier 59).

Tal como Jorge Alberto Manrique ha trabajado la cuestión del manierismo y Barroco en Nueva España. Remito al tercer volumen de su libro Una visión del arte y de la historia.

Con "suceso de escritura" me refiero a un tipo específico de y escaso de texto cuya a aparición produce un cambio en el estado de las cosas o en el horizonte de mundo. En este caso, dos cartas que anuncian que el mundo cambió definitivamente, sin posible retorno a su estado anterior. Más claramente, cambian el mundo al tiempo que anuncian que lo están 
a pedazos, enmascarado, bordeado y bordado de monstruos y quimeras, de manera antinatural y a-teológica, eclosiona el verdadero mundo geográfico y el nuevo mundo en su estadio global-moderno. Los dos hitos iniciales: la carta de Cristóbal Colón a Luis de Santángel del 15 de febrero de 1493 y la carta Mundus Novus, publicada en París en 1504, escrita o atribuida a Américo Vespucio; documentos éstos en los cuales se atisba y luego se afirma que el mundo no era como lo pensaron e imaginaron siglos y siglos de cultura, siglos y siglos de historia espiritual. La primera de estas epístolas corresponde al máximo estadio de la imaginación del mundo no-global, al pivoteo e indefinición de "lo real" entre la ecúmene cristiana y Cipango. Atañe, sobre todo, a un momento de suprema desobediencia filosófica y teológica ${ }^{4}$, en virtud de la cual la imaginación excedida intuye que sobre ella y su plus ultra hay un "más allá", un borde externo e incógnito en donde recién se inicia la realidad. La segunda epístola comunica la destrucción de la ecúmene tripartita (Asia, África, Europa) y el fin de la geografía teológica judeocristiana; el advenimiento del mundo desacralizado-moderno-global y la emergencia del nuevo real para la filosofía, la teología, la historia y el arte. Comunica en definitiva, la emergencia de lo-el otro ${ }^{5}$, tanto como la transformación de lo Uno en lo Otro: del mundo, la cultura y la conciencia en otros.

En analogía con los enmascaramientos, borramientos y desplazamientos de esas Letras y su parábola Fin de Mundo precolombino (americano y europeo)/ Indias/Nuevo Mundo, la productividad cultural observable en América exhibe una contextura extremadamente heterogénea, irregular, informe, de estructura abierta, de territorios oscuros. Productividad fallada (para la pulsión hegemonizante), que compuso un territorio en el que se visualizan centros (emplazamientos virreinales), bordes, desplazamientos, fronteras (el

cambiando. En tal sentido, estas cartas producen una "catástrofe de mundo", al tiempo que de ellas surge el nuevo mundo: el mundo moderno.

Dicha desobediencia se ejerce contra las Sagradas Escrituras, el pensamiento platónico, aristotélico, ptolomeico y el de los Padres de la Iglesia.

El Otro en su radicalidad: “....si vieses cosa tan insólita y a un monstruo semejante”. El Otro, portador de una atrocidad sexual sin repertorio aun en el pecado: "Otra costumbre hay entre ellos muy atroz y fuera de toda credulidad humana..." El Otro, señor de sí mismo, sin rey o autoridad que lo subyugue, ni sistema comercial identificable por el europeo. Desde la sexualidad, pasando por la organización social, hasta lo teológico, el-lo otro como lo monstruoso-antisistémico, lo otro de la ley (Vespucio 181-183). 
Reino de Chile, por ejemplo) y valles blancos sin suceso en la letra ${ }^{6}$. También múltiples zonas sombreadas, obliteradas en la propia opacidad; obturadas por la temporalidad de la ruina súbita del mundo que deja de ser: aquello que en Chile el enunciante del Cautiverio Feliz de Francisco Núñez de Pineda y Bascuñán observa retirarse para siempre al fondo de la materialidad sin sentido, a la condición de resto ${ }^{7}$. Esta ruina incluye la degradación de la naturaleza sacra (la Pachamama) a la condición (aprovechable) de mercancía: naturaleza arruinada, desde el primer momento ${ }^{8}$ financista de la guerra europea. Todos, centros, fronteras y opacidades, organizados alrededor de un centro vacío: la noticia e imposición sin fe ni revelación del nuevo dios (el cristiano-católico), y un centro ausente: el nuevo poder absoluto, total, del monarca español, cuya existencia en América, de principio a fin, no fue otra cosa que un acto puro de lectura-escritura9. Vacío, ausencia y signo constituyen el eje del "Nuevo Mundo", dinamizado, sin embargo, por la emanación proliferante, metonímica hasta la extenuación, de las copias. Por los simulacros del centro presente (adelantados, virreyes, capitanes, gobernadores, etc.; evangelizadores, órdenes religiosas, obispos, alférez, cofradías, etc.) y por la disimulación del silencio teológico que se abate sobre el mundo: la insuficiencia oracular de todos los dioses, los precolombinos, mayores y menores; el judeo-cristiano, del Antiguo

6 El silencio, la ausencia, lo desconocido operantes, hacia donde llama la atención José Lezama Lima en sus críticas de arte. Silencio de grandes territorios, culturas e imaginarios, pero también el silenciamiento que el nuevo nombrar de las palabras propina a los entes, los animales y las cosas (197-9). Por ejemplo, el colibrí silenciado al interior de la palabra "Huitzilopochtli" pronunciada por el español (Bernal Díaz del Castillo. Historia verdadera de la conquista de Nueva España). También las dimensiones de lo divino silenciadas cuando el evangelizador pronuncia la palabra "Pillán" en el Cautiverio Feliz.

"Resto": el intento de Carlos de Sigüenza y Góngora de restituir la imagen del "colibrí" al término Huitzilopochli, disimulando el campo semántico que refería a la divinidad mexica (Carlos de Sigüenza y Góngora. Teatro de Virtudes Políticas, 195-196). Ese término es el "resto" que queda después que la divinidad se ha retirado de él y de la pequeña ave palpitante. También el "mundo arruinado" (mapuche; hispánico-católico) en que habita de Pineda y Bascuñán: "todo esto no es hoy una montaña y un tupido y cerrado bosque inhabitable, porque le han echado leña sin haberla menester" (945).

Primero: la intención de Colón de financiar con oro o esclavos la guerra para reconquistar Jerusalén (Colón, Cristóbal. Textos y documentos completos. Relaciones de viajes, cartas y memoriales). Después, la guerra continua de España en Europa.

9 El famoso Requerimiento, cuya lectura en voz alta funcionaba, según la monarquía española, como dogma de sometimiento del Otro a su poder. Esto es un suceso de lectura. Luego, las leyes de Indias. 
y el Nuevo Testamento; los africanos múltiples; divinidades ensimismadas todas ellas que no profetizaron su repentina convergencia en la emergencia cuatripartita -global- del mundo. Más aun, que no profetizaron su encuentro con su Otro radical: el no-dios, el Vacío Oriental. Disimulación teológica, tupido velo, para encubrir el mestizaje divino que acaece en el horizonte global, sobre el cual luego se simulará (hasta que toma forma y existencia) el rostro sin rostro de un solo dios, el dictum de su verbo universalizante. De tal manera que la primera perla irregular, la primera esfera deformada, corroída, que se avizora en el horizonte barroco es la que se produce y proyecta desde el "nuevo mundo" y se conoce como el Orbe Católico: aquella esfera teológica, auténtico barrueco, que simula su completitud en la tierra y su perfección en la trascendencia. Barrueco que exige hoy una redefinición: el "Nuevo Mundo" no es un lugar; no es América, ni los emplazamientos europeos en África o el Asia, ni algún otro lugar geográfico. El "Nuevo Mundo" es el horizonte donde acontece, simultáneamente, para todos, el nuevo real ${ }^{10}$.

Si queremos considerar el trabajo de lenguaje o sobre el lenguaje como sustrato poético de los tres momentos barrocos americanos, es menester hablar primero del límite del lenguaje que lo antecede y de lo que ese límite manifiesta, pues solo a partir del silencio que acaece a su interior (incapacidad de significar) podemos comenzar a hablar del exceso barroco o exceso del significante.

A finales del siglo XV y durante el XVI, la situación de límite que refiero señala aquella experiencia de realidad que no se puede o no se sabe instalar en la conciencia porque esa realidad y su experiencia habitan y se verifican en un más allá de las palabras. Sin que exista un orden jerárquico en la siguiente enumeración, sino más bien eventual, el límite del lenguaje se manifiesta en el valor epistémico (negativo, por cierto) que cobra el tópico "no tengo palabras" como experiencia de caducidad del campo conceptual europeo frente a la realidad cultural y natural de los nuevos mundos y frente al Otro. Simultáneamente, del Otro lado (americano), ese límite se hace insalvable (traumático en estricto rigor ${ }^{11}$ ) con el destierro de la(s) lengua(s)

11 Es importante comenzar a hablar del trauma del lenguaje en América y del español americano como metáfora y re-presentación de una pérdida. Al mismo tiempo, observar la resistencia de las sintaxis y gramáticas al interior del español americano como residuo persistente y operante de ese trauma, especialmente en las poéticas barrocas desde el siglo XVI hasta hoy. El trabajo del poeta neobarroco Héctor Hernández acentúa de manera general 
madre por imposición de otra para nombrar la propia realidad. Luego, sobre el lenguaje que queda (el resto), la evangelización política cristiana impone la censura ${ }^{12}$, la retirada y confinamiento del sentido al interior de las palabras para nombrar y nombrarse ${ }^{13}$. Para la(s) lengua(s) prehispánicas, pérdida del vínculo entre la palabra y la cosa; pero también inusitado multilingüismo intracontinental, producto de los desplazamientos forzados de grandes sectores de población indígena al interior del continente. Al mismo tiempo y a una escala sin precedentes, por primera vez en la historia moderna, multilingüismo intercontinental con la llegada de las lenguas vernáculas europeas (incluyendo el latín), africanas y asiáticas. Desplazamientos múltiples que generaron la multiplicación de vocabularios, sintaxis y gramáticas en la base lingüística y cultural de la primera sociedad global del mundo moderno: la Colonia americana.

Estos y otros hechos, quizá más sutiles o brutales, más profundos y propios de la(s) Historia(s) de la(s) de la(s) Lengua(s) - que también es (son) la Historia de la Guerra-, dieron lugar en América a una inédita proliferación de palabras sin raíz ni campo semántico común, que gravitaban -competíansobre los fenómenos y las cosas, de tal suerte que lo que la proliferación de los significantes expone es la tensión máxima de todos los logos en el nuevo horizonte de la experiencia para la cual no hubo palabras, o para la cual hubo demasiadas palabras: el mundo o la metamorfosis del mundo, a partir de 1493. En el orden del lenguaje -y del sentido, por supuesto-, el exceso barroco señala y disimula una fuga semántica cuya dimensión y consecuencias llevan a la conciencia radical de la lengua como código, vaciado de toda relación necesaria -teológica, cultural, histórica- entre la palabra y la cosa. En definitiva, lo que se encuentra en el trabajo de lenguaje del primer Barroco (siglo XVI), es la proliferación del significante y la reinvención de su vínculo con la realidad; la expansión de la metáfora y la decantación metafórica de lo que llegará a ser lo real en el lenguaje -o de lo que el lenguaje señalará

la persistencia y resistencia a las que me refiero, cuando, por ejemplo, habla de "un castellano medio mapudungun" en el poema "Querido impostor" perteneciente al libro El barro lírico de los mundos interiores más oscuros que la luz.

12 El instrumento oficial que filtra el significado es el famoso Cuestionario aplicado por los evangelizadores-conquistadores.

13 De un momento a otro, ya no ser mapuche ("hombre de la tierra"), sino araucano (?), por ejemplo. 
como "real"-, elementos propios del Barroco americano desde el de Indias hasta el actual.

Si hablamos del trabajo de lenguaje, brevemente debemos hablar del trabajo de escritura. De un lado, aquel de llevar a la escritura lo que nunca antes estuvo en la escritura (ni en la sagrada, ni en la profana, científica o filosófica); es decir, lo que significó (re)presentarlo irrepresentado (informe, excesivo, lo de afuera) en el alfabeto latino: nuevamente, el mundo. Por otro lado, en concordancia con la expulsión de las lenguas madre y el confinamiento del sentido al interior (inescrutable) de sus palabras, se encuentra el trabajo letrado -entre el latín y el español; entre indígenas y evangelizadores- que hace aparecer las lenguas expulsadas como escritura. En el primer caso, supremacía del género oscuro, caos en la sintaxis y emergencia en ese caos de una nueva episteme (la ciencia moderna). En el segundo, trabajo que compone la lengua como reliquia en el alfabeto, exhibición museal de una escritura sin mundo, de la palabra sin etimología.

Por lo tanto, más que el florecimiento de un tipo de cultura en América (barroca, hispánica, occidental o católica, mestiza, criolla, afro, asiática y sus aleaciones) debe observarse el Orbe Indiano como un campo de "condiciones de borde" caracterizado por una ley de tensión-deformación ${ }^{14}$, en el cual todos los modelos culturales (y su lenguajes) fundados en el concepto de unidad (los precolombinos europeos, los precolombinos americanos, africanos, ¿asiáticos?), fueron sometidos a la experiencia de sus propios límites y redefinidos por ellos. En ese borde, los modelos culturales se reflejaron, duplicaron, interfirieron, alteraron, copiaron e interceptaron en distintos grados; en consecuencia, se vaciaron los unos a los otros y los unos en los otros hasta transformarse en otros vaciados de sí: en simulacros de carácter múltiple y abierto, pero sobre todo -menos filosóficos-, en simulacros mestizos y sobresaturados ${ }^{15}$.

14 Concepto científico de condiciones de borde: "Contrariamente al caso de los problemas de condición inicial, no existe una teoría que asegure la existencia de solución para este tipo de problemas. Por tales condiciones se entienden aquellas que definen el comportamiento del modelo en sus límites. Extendiendo el caso de la generación de fuentes de campo, puede verificarse fácilmente que la imposición de potencial constante en un contorno implica un campo paralelo al contorno" (Fuente: documento de la Facultad de Ingeniería de la Universidad de la República de Uruguay http://www.fing.edu.uy/inco/cursos/numerico/ed/CB.doc).

15 Me refiero, por ejemplo, a la definición del sujeto por el traje en la Colonia. En cuanto la dinámica del mestizaje impedía saber a ciencia cierta si alguien era y en qué grado 


\section{$E L-L O$ BARROCO}

En cuanto la racionalidad barroca es aquella forma del pensamiento que se forjó en "condiciones de borde" y se desarrolló en el trayecto de lo uno a lo múltiple ${ }^{16}$, no suscribo la exigencia objetivista que demanda separar, clara y distintamente, la reflexión de su objeto, el Barroco de lo Barroco. Con esto quiero decir que no sostengo la idea de que "lo Barroco" sea algo abordable teóricamente desde fuera $\mathrm{y}$, en consecuencia, sea algo (una obra o un conjunto de obras, cualesquiera que sean) susceptible de ser elucidado (positiva o negativamente; fragmentariamente o no) por uno u otro discurso teórico escindido del objeto. En mi aproximación al problema, el campo conceptual ("el Barroco"), el ejercicio teórico (qué es), su racionalidad múltiple (incorporación del nuevo real), y su condición histórica, son sustanciales a "lo Barroco", en cuanto inherentes a una densidad poética y acaecimiento de lenguaje ( $\mathrm{del}$ mundo en el lenguaje) que necesariamente debió generar su propio horizonte de visibilidad en plurales y simultáneos planos y superficies de inscripción, de tal manera que la obra elabora el marco teórico conceptual que la propone como obra, tanto como ésta materializa dicho marco (lo pone en expresión). Para que esta afirmación no quede en el aire, cito, por fundacional, el Arco de Triunfo Neptuno Alegórico, Océano de Colores, Simulacro Político (1680), de sor Juana Inés de la Cruz: obra plástica, arquitectónica, escultórica, inscrita en el plano político-social de la celebración y erigida en medio de la urbe (México-Tenochtitlan) como monumento y discurso. También escritura y textualidad extensas y plurigenéricas que afirman y tensionan los dispositivos del saber-poder y del poder para representar. Al mismo tiempo, densidad poética inscrita en el plano conceptual como reflexión teórica concerniente al problema de la representación: del concepto en la "cantidad limitada"de la materia; de lo invisible en "forma visible". Principalmente, poética barroca -Razón de la Fábrica Alegórica y Aplicación de la Fábula- que explica la

mestizo, mulato, criollo o español, y cuál era su lugar en la estructura social, el traje vino a ser el elemento definitorio del "ser". Del mismo "ser" que podía mudar con el traje para devenir en otro: exterioridad pura, travestismo fundacional.

16 La forma discursiva propia del hiato es el Género Oscuro: aquel que busca describir un objeto para el cual no se tiene referencia, sin embargo busca referir lo real. Asimismo, le es propia la dislocación del conocimiento por semejanza. Reúno en el término "racionalidad" las operaciones analíticas, reflexivas y conceptuales que permitieron abordar la otredad radical de la naturaleza y agenciarla en el orden del pensamiento. 
obra como copia y sienta lo propio del arte en el reino de los simulacros y de la imaginación: en "las sombras de lo fingido" y "en toda la latitud de lo imaginado". Por último en esta enumeración (no en la obra misma), poética que se inscribe en la superficie teológico-filosófica del siglo XVII colonial para señalar y transgredir las fronteras entre la tríada fundamental, naturaleza, cultura y divinidad, en tanto concibe y presenta estos tres elementos como entidades autorales y agentes equivalentes de representación. Si bien se pueden decir muchas cosas más del Neptuno, observar en este Simulacro Político el devenir de la obra en aparato teórico y viceversa permite entender que ya en el siglo XVII colonial "Barroco" es una densidad poética rizomática que se inscribe teórica y materialmente en los distintos planos de un mismo objeto y en ese devenir extrema el objeto-concepto hasta el punto en que este se transforma simultáneamente en múltiples otros: en pintura, escultura, poesía, y discurso. En objeto efímero y transhistórico a la vez.

El-Lo Barroco también es una densidad poética inscrita en y como superficie de lectura, en cuanto producida por la articulación y roce de un conjunto localizado de obras y un ejercicio histórico y transhistórico, sincrónico y diacrónico, de relecturas, observable desde el siglo XVI en América y el mundo. Lo que esa dinámica emana (otra forma de rizoma) constituye un tejido cultural referible y abordable, que podemos reconocer suficientemente como Barroco y desplazar desde la metamorfosis global iniciada de finales del siglo XV ("temprana modernidad"; "primera globalización" ${ }^{17}$ ) hasta su neologismo actual, Neobarroco. Refiero, específicamente, el tejido poético-ensayístico que comunica, cohesiona y permite reconocer -sin lugar a dudas- el trabajo de sor Juana Inés de la Cruz (y la lectura que hace Octavio Paz de la monja), el de José Lezama Lima (y la lectura que hace de la misma monja), el de Severo Sarduy (la lectura que hace de Lezama y Paz), el de Néstor Perlongher (la lectura que hace de Lezama y Sarduy), y el de Roberto Echavarren (actual lectura de la monja y de Perlongher, etc. ${ }^{18}$ ), el de Javier Bello (lectura de todos los anteriores y de la monja), como poéticas adherentes y afines; así como apropiaciones semejantes del lenguaje y sintaxis disruptivas de la equivalencia realista entre palabra y realidad. (Re)lecturas que inventan su

\footnotetext{
17 “Temprana modernidad” y "primera globalización” no refieren lo mismo. El primer término indica una crisis epistémica; el segundo, su escala mundial.

18 Pongo por ejemplo el tejido de lecturas evidente entre estos autores solo para trazar una línea, pero eso no quiere decir de ninguna manera que sea el único trazo, sino más bien, como dije, en un tejido rizomático.
} 
propio devenir ${ }^{19}$, que aportan al campo sus particulares adhesiones y, en su anverso, producen obras que a la percepción se presentan inequívocamente Barrocas.

En las mismas coordenadas, establezco la equivalencia entre Barroco y metamorfosis, pues en la transformación del mundo no-global al mundoglobal, se encuentra su elemento más propio, su operatoria y su movimiento. Lo uno y lo otro son inseparables; la metamorfosis es el origen histórico del Barroco, tanto como es la estructura histórica que el Barroco refleja y expresa. La radicalidad de esta afirmación se entiende si exponemos ciertos hechos: la globalidad, tal como la percibimos o experimentamos hoy, esto es, de manera total, se inicia en 1564, con una expedición que parte de Nueva España (México) hacia el oriente, impulsada por la urgencia de llegar, finalmente, al objeto de deseo, la seda, las especies y mercancías de la China ${ }^{20}$. Este y no otro es el viaje que inaugura el intercambio a escala global y México, su origen y diáspora, es el primer enclave de esa globalización ${ }^{21}$. El cordón que completa el intercambio, el ouruboros y sierpe del deseo para orientales y europeos, es la plata americana: el Potosí duplicado por los dos grandes virreinatos indianos, Nueva España y Perú. En el proceso globalizador, el mismo deseo de oriente es el motor que impulsa la emergencia del Reino de Chile, la Guerra de Conquista contra Arauco, el viaje al sur, hacia Magallanes, que vertebra la geografía chilena ${ }^{22}$.

Si la transformación cultural y económica ${ }^{23}$ que produce el viaje de 1564 hacia oriente es formidable, no es menos espectacular la que engendra en el orden de la naturaleza, en donde adquirió las dimensiones de catástrofe:

No me interesa establecer "un aire de familia" en el Barroco americano, pero sí un "desarrollo de lectura". Por supuesto que ese "desarrollo de lectura" incluye a muchísimos más narradores, poetas y ensayistas que no menciono aquí con el único afán de contener en este momento la fructífera dispersión.

$20 \quad$ Este fenómeno ha sido trabajado por Rubén Carillo en un reciente ensayo, "Asia llega a América. Migración e influencia cultural asiática en Nueva España (1565-1815)”, en la revista digital Asiadémica.

21 AAcapulco llegan las primeras embajadas de oriente en búsqueda del intercambio. En este puerto "convergían las cuatro partes del mundo", afirma Serge Gruzinski en Las cuatro partes del mundo: Historia de una mundialización.

22 El primero en realizar este viaje al sur es Pedro de Valdivia. Remito a la edición de Mario Ferreccio de las Cartas de Relación de la Conquista de Chile.

23 La plata americana triplica la circulación de metales preciosos en el mundo. Así lo afirma Charles Mann en su libro 1493: Una nueva historia del mundo después de Colón. 
la catástrofe inherente a toda metamorfosis. Con la plata y las especias se intercambian animales, plantas, insectos, microorganismos, virus, enfermedades, plagas, depredadores, etc. ${ }^{24}$, y se desencadena la hecatombe ecológica de donde surge, distinta de su natural devenir, transfigurada, heterogénea, la naturaleza moderna. Un hecho de esta magnitud, por supuesto acarrea todo tipo de consecuencias, marca un antes y un después en la cultura, señalando un espacio de ruptura. En virtud del hiato que se abre entre naturaleza dada por Dios y la naturaleza intervenida-(repentinamente)trastocada-mutada-Otra, se instaura una interrogación y una ilegibilidad teológica ${ }^{25}$ nunca resueltas en el corazón de la fe (prehispánica, cristiana); se enturbia hasta lo indiscernible la correspondencia micro-macrocosmos, y se da lugar a una nueva experiencia de mundo desasida de cualquier imperativo esencial.Para las culturas prehispánicas, en la cuales los hombres y los dioses compartían el mismo alimento (el maíz, por ejemplo), el quiebre entre naturaleza y divinidad, su silencio repentino en la naturaleza, fragmenta el eje cosmogónico de la cultura y en la conciencia del sujeto da lugar a la primera experiencia americana de la muerte de Dios ${ }^{26}$. A partir de la metamorfosis del sustrato natural, la cultura europea-católica entiende la imposibilidad de fundar el nuevo orden natural en las Sagradas Escrituras y concibe la idea de naturaleza como artificio, librada al quehacer humano. También comprende que, de ahí en adelante, el poder dependerá del establecimiento de otro tipo de soberanía acorde al nuevo real desacralizado de la naturaleza y asigna a la nueva concepción no-adánica del lenguaje la tarea de restituir la referencia; es decir, de proponer en el orden de la cultura

$24 \quad$ Gonzalo Fernández de Oviedo afirmaba en su Sumario de la Natural Historia de las Indias (LXXV), que el "mal de bubas", la sífilis, se había conocido en Europa tras el regreso de Colón y luego don Gonzalo Fernández de Córdoba la habría llevado a Italia. Es curioso señalar que Oviedo notó que los nativos no enfermaban o se curaban con mucha facilidad y que recomienda a los europeos que enfermen de este mal que se procuren guayacán de la Isla Beata, cerca de Santo Domingo, del mismo modo que advierte: "de ninguna manera se pega tánto como del ayuntamiento de hombre a mujer, como se ha visto muchas veces, y asimismo de comer en los platos y beber en las copas y tazas que los enfermos de este mal usan, y mucho más en dormir en las sábanas y ropa do los tales hayan dormido" (119). El miedo al contagio en este contexto de globalización puede tenerse como antecedente de la expansión del SIDA en nuestra época y cómo influyó en ciertas poéticas neobarrocas, por ejemplo, en el caso chileno, la de Pedro Lemebel, en Loco afán: crónicas de sidario (1996), principalmente.

$25 \quad$ ¿Cómo leer en la naturaleza la voluntad de Dios cuando es el hombre quien la modifica? ¿Cómo entender el vínculo entre el Creador y su creación?

26 La segunda (la Ilustración), al parecer, fue más bien nominal, no importó tanto. 
una nueva equivalencia entre artificio y artificio, entre el código (lingüístico, plástico) y lo natural ${ }^{27}$. Parafraseando la célebre frase del desesperado Pascal en su fase más cristiana (y que Lezama, el inventor del cristianismo poético, hace suya), podemos decir que perdida (nuevamente ${ }^{28}$ ) la primera naturaleza, para el barroco todo es Paisaje, Cultura, inscripción de un inusitado despliegue poético-metafórico del lenguaje sobre la superficie de una ausencia. El-Lo Barroco, con todas sus variantes, emerge como experiencia y legibilidad de esa portentosa y caótica transformación de la naturaleza. Asimismo, como legibilidad de la huella que dejó en el espíritu la doble fuga de la naturaleza: a los ámbitos indecibles de lo sublime; a los proliferantes de la mercancía.

Intempestivo, arbitrario, sin fragua en el tiempo, el imaginario barroco es también indisociable de la metamorfosis de efectos globales iniciada a finales del siglo $\mathrm{XV}$, sin embargo, en ese arrítmico transcurso se reconocen particularidades y muy distintos procesos culturales y simbólicos. Al imaginario barroco americano, quizá como ningún otro, lo amasa la violencia y lo particulariza el vuelo de la imaginación. En él, lo uno y lo otro, muchas veces, son inseparables. Se trata, de un lado, del despliegue cognitivoimaginativo -sin precedentes- realizado por los alumnos de los "Colegios de Naturales", misiones o repartimientos de indios para incorporar sin ningún antecedente, referente o mapa mental el trivium (la lógica, la gramática, retórica) y el quadrivium (aritmética, geometría, música y astronomía), la arquitectura, escultura, la pintura, etc., europeas. También se trata de la violencia simbólica que implicó la incorporación de los signos con que la cultura europea quiso significarse en el "nuevo mundo" y que en su expansión llegó a imponer y (auto)denominar hegemónicamente en el mundo global como "el saber universal" 29 (hasta hoy). Pero, por sobre todo, el Barroco de Indias se distingue por el despliegue de la imaginación teológica a partir de

$27 \quad$ Véase de A. Hauser, Manierismo. La crisis del renacimiento y lo orígenes del arte moderno.

28 Sin duda, la naturaleza americana revivió en la conciencia europea cristiana el recuerdo del Jardín del Edén, desde Cristóbal Colón hasta el siglo XVII. También la idea de la expulsión por el pecado, desde Bartolomé de Las Casas en adelante. Para la conciencia europea, la naturaleza americana encierra una profunda conciencia del pecado. Quizás, por esto, trabajó tan afanosamente para eliminarla de "la historia del espíritu" (europea).

29 En la violencia del saber y del arte universal, también hay que incorporar al Barroco Jesuítico y su red de conocimiento global. Ver el libro de Teófanes Egido, Los jesuitas en España y el Mundo Hispánico. 
la cual los "naturales" pudieron representarse la brutal escisión judeocristiana entre cuerpo y espíritu que se les impuso e internalizarla como su nueva alma cristiana. El alma del Otro: aquello que fue la última utopía evangélica y el non plus ultra de la voluntad universalizante de las culturas cristianas católicas romanas. También su condición aberrante de esclavitud. Por supuesto que la invención del alma del indio implica otra violencia: la de la historia como expulsión de la naturaleza. Y la violencia imaginaria de entrar súbitamente en el flujo histórico de esa expulsión.

Lo que se encuentra en la base del imaginario barroco americano es: escritura sin significado; filosofía sin "verdad"; arte sin gusto; cultura sin dimensión simbólica; historia sin memoria. Relato, relato, relato. E invención: de la verdad, el gusto, lo simbólico, la memoria; del Alma cristiana del indio y de su condición de posibilidad: el $\mathrm{Mal}^{30}$. También la incorporación imaginaria del repertorio judeocristiano de representaciones del mal y el castigo $^{31}$ que trajo consigo la aniquilación del cuerpo precatólico (en particular el de los sacerdotes) en el que los dioses se presentizaban ${ }^{32}$. Alma y signo, la disyunción irreparable: el significante y el significado, el espíritu y la materia. Todo aquello en relación con la nueva ubicación de la divinidad, la "del dios externo", localizado en un más allá. Después de la muerte de los verdaderos dioses precolombinos, la única posibilidad, o la única imaginación posible de lo trascendente la proporcionó el arte: las estampitas borrosas en las que -aun con el fervor del duelo- hubo que volver a imaginarse lo divino, pero como lo Otro: la virgen en México y en toda América y, en el norte de Chile La Tirana, por ejemplo. Luego, los Cristos-Llaga del Barroco indiano, cuya piel máximamente fistulada no deja ninguna duda de que los dioses mueren: los precolombinos; el cristiano. Relato, representación y significantes puros para la violencia y la fantasía en el principio y origen del imaginario barroco americano.

\footnotetext{
30 La demonización de toda las creencias precolombinas, por lo tanto, la necesidad de "salvar".

$31 \quad$ Aquí habría que hacer un alto y hablar largamente de la erradicación de la sexualidad precatólica americana, pecaminosa, según todas las crónicas; es decir, libre. Comenzar a hablar del erotismo y del homoerotismo propios de las culturas americanas precatólicas y su relación con lo trascendente podría ayudarnos a comprender y comprometer otras fuentes de la erótica neobarroca contemporánea.

32 Como antes lo hicieron en el Zemí (taíno) o en el Machi (mapuche).
} 
Desafortunadamente, desconozco cómo, en algún pliegue de la seda proveniente de Manila, en la Nao de la China, llegó el capullo de la Vacuidad (lo no-dios) y cómo "el natural" imaginó esa Nada; sin embargo la encuentro desenvainada, ilegible, en la suntuosa decoración de la vajilla poblana, en "La Biblioteca como Dragón", de Lezama, o en la segunda parte de Cobra de Sarduy. A la seda misma, la encontramos en las vírgenes vestidas con kimonos en las iglesias de Ouro Preto y Sabará, también en los trajes y zapatos que lucían las élites femeninas y masculinas virreinales.

\section{MEMORIA DEL OLVIDO: LA HISTORIA}

El tejido de lecturas del Barroco americano, la correspondencia entre globalización y metamorfosis que encierra, la gravitación exponencial de los significantes sobre el nuevo real y su condición imaginaria no solo sientan la "cuestión del Barroco" como un asunto de gran vitalidad entre nosotros; además llaman la atención sobre el hecho de que tal cuestión no puede ser deslindada de una historicidad que reconoce tanto su permanencia en los siglos (XVI-XVII) como reclama su sentido en la actualidad (siglo XXI). En otras palabras, la vitalidad del Barroco en América obliga a preguntarse por sus relaciones con la historia.

Si bien la permanencia barroca en nuestra cultura es inapelable ${ }^{33}$, también es cierto que se trata de un fenómeno cuyas súbitas apariciones, tanto en el siglo XVI como en el XX y XXI, tensan la noción misma de historicidad. El Neo-barroco da razón de sí como otra vez el Barroco y repone el primer Barroco como una falla de la cultura y de la historia, de tal manera que señala otra vez la falla y a sí mismo como la expresión de ella. En este sentido, obliga a pensar la cultura (la nuestra) como un fenómeno de cortes profundos (e invenciones casi simultáneas) que en más de un momento (comenzando por su intempestivo origen americano) no obedece a la idea de desarrollo o a la

33 Esta permanencia también puede ser entendida como insistencia de lo negadoexcluido en nuestra cultura, en nuestra historia. En este sentido, puede ser leída la reciente antología Indios del espiritu (compilación hecha y prologada por Roberto Echavarren, con un postfacio de Adrián Cangi) de poetas del Cono Sur como Héctor Hernández, Reynaldo Jiménez, Amanda Berenguer, Wilson Bueno, Perlongher, el mismo Echavarren, etc.). En conversaciones con Roberto Echavarren, éste ha afirmado que el título de la antología estaría inspirado en el ensayo de Patricio Marchant "Atópicos", "Etc." e "Indios espirituales": Notas acerca del racismo espiritual europeo. 
ilusión sucesiva que implica la noción epocal, sino a la dinámica aleatoria velocísima-de fenómenos históricos altamente disruptivos. Simultáneamente, contradiciendo la falla y su síncopa, las apariciones del Barroco - de Indias; de la primera mitad del siglo XX; el conjunto de variaciones neobarrocas encabalgadas en los siglos XX y XXI-han generado una suerte de metamorfosis (hasta ahora) sin solución de continuidad en nuestra cultura, que recorre a contrapelo de la dinámica tradición/ruptura observada por Octavio Paz en la literatura latinoamericana. En palabras simples, el Barroco re-aparece siempre y siempre otro en nuestra cultura para decir que la falla se re-produce en ella, y en ese decir señala su permanencia tanto como la de los sustratos históricos de la falla. De tal suerte que la metamorfosis sin solución de continuidad se despliega también como una memoria de larga duración particular. Una que reconoce su genealogía -y la repone- en el lugar en el cual acaece una pérdida histórica y se opera una transfiguración en la cultura. Memoria de punto ciego, también podemos decir, que se activa cuando está acaeciendo un cambio de piel de la historia (por eso en el Barroco latinoamericano la ruina es origen); y cuando la cultura adviene como otra (por eso también en Latinoamérica la poética barroca es fundacional).

En esta circunstancia, ¿cómo pensar el Barroco y el Neobarroco, su urdimbre -al decir de Lezama- y sus múltiples variaciones-reinvenciones desde el siglo XVI hasta hoy en Latinoamérica? ¿Cómo pensar su transhistoriedad? Es cierto que en las últimas décadas la actualización neobarroca ha proliferado denominaciones -desplazamientos al interior del neologismo: neobarroco, neobarroso, neoborrroso, neobarroco fronterizo-y que esa expansión conceptual -en la que cualquier y ningún fenómeno puede ser tildado de barroco- ha llevado a algunos a negar su pertinencia o a restringir su observación a un cierto abanico de procedimientos más o menos presentes en determinadas obras. La reticencia o pretendido rigor que ahí se observa deja de lado el hecho de que la expansión conceptual ha corrido de la mano con la incorporación de nuevos territorios geográfico-culturales (Argentina, Brasil, Uruguay, Colombia, la cuenca del Mar del Plata, etc.) a "la cuestión del Barroco", por lo tanto desatiende que tales territorios tienen un sustrato cultural específico en los siglos XVI y XVII ${ }^{34}$, una compleja reminiscencia de sí y de su heterogénea

34 Aclaro que en este trabajo solo puedo considerar los fenómenos culturales acaecidos con posterioridad a 1492, lo cual no significa, en ningún caso, desconocer la cultura indígena ni los procesos que interrumpieron su desarrollo. 
incorporación al "Orbe nuevo", moderno, de la primera globalización. Pero por más que se le quiera dar la espalda a este asunto, el hecho es que cada uno de esos territorios tiene y trae a la producción neobarroca contemporánea una historia particular, una sensibilidad, un sustrato residual, que espesa y enriquece la discusión. En definitiva, una memoria que se interpela y dialoga consigo misma, tanto como una historia de la lengua que desde mi punto de vista no se puede obviar. ¿Qué esos territorios han llegado después a la discusión sobre el Barroco y el Neobarroco y se incorporan introduciendo forzosas modificaciones? Pues sí, arriban a la discusión neobarroca de la misma manera aleatoria, desplazada en que se produjo el primer Barroco en los distintos - próximos y lejanos- territorios coloniales -Chile, por ejemplo-. Con la misma disparidad con que arriban a la actual globalización.

\section{BARROCO Y TRANSHISTORIEDAD EN CHILE}

Esta última afirmación me obliga a detenerme en dos textos muy diversos que conocí recientemente y que llegaron para tejerse a la escritura de este ensayo. El primero es "Nota para una cierta poesía latinoamericana actual", de José Kozer, y el segundo, "El mundo es plano, después de todo...", de Thomas L. Friedman ${ }^{35}$. La Nota de Kozer destituye la centralidad que tuvo la metonimia en la poesía latinoamericana del siglo XX, toda vez que, "[e]ste sistema de expresión en nuestro momento histórico, dada la complejidad material de la vida, el devorador de la tecnología con sus cambios y bruscas, aceleradas alteraciones, se vuelve insuficiente". De otro lado, Friedman aborda la "tercera era global" desatada por la plataforma tecnológica india y señala que su radical actualidad tiene su antecedente en el viaje de Cristóbal Colón hacia la India. Según su análisis, en esta fecha se inicia la primera era global y en el 2005 se inicia la tercera y el mayor aceleramiento que haya conocido la historia de la humanidad. El punto es que Kozer, desde la poesía, y Friedman, desde la tecnología y la geo-economía, coinciden plenamente al ver en "el devorador de la tecnología" el detonante de una transformación sin precedentes que vuelve a afectar la estructura global (en

35 El texto de Kozer aparece publicado por primera vez en este número monográfico de la Revista Chilena de Literatura. El texto de Friedman fue publicado en el New York Times el 3 de abril de 2005 . 
la que vivimos hace quinientos años) y la vida de los individuos. Lo que me interesa resaltar es que a partir de aquello, Kozer detecta un movimiento, un cambio en la estrategia retórica del Neobarroco más reciente, arriesgado y experimental: una nueva violencia en su sintaxis. A esto debemos agregar: esta violencia tiene memoria en el lenguaje, ahí se encuentran, para luego divergir, el Barroco y el Neobarroco latinoamericanos.

En este marco de esa violencia (de la sintaxis, de la historia) me interesa reflexionar acerca de la productividad barroca en un territorio en el cual El-Lo Barroco ha provocado un silencio crítico, un efecto de vacío y de transparencia sorprendentes: Chile, y en particular la literatura chilena.

A partir de los años 70, como todos sabemos, Chile se convirtió en el laboratorio en el que el capitalismo puso a prueba su fase más extrema, antes de propagarla a nivel mundial. Es decir, ensayó aquí sus "condiciones de borde" para definir en sus límites (escenario de máxima desregulación) su fase más avanzada: la libertad absoluta del capital. El éxito obtenido (el corte histórico; la transformación de la historia) determinó que la estructura social, económica y comunicacional del Chile de las últimas décadas sea la del neoliberalismo global, necesariamente articulada a los códigos, lenguajes, velocidades, ritmos, simultaneidades, formas de comunicarse y ser de la plataforma digital. También determinó que sea una estructura acorde, abierta y dispuesta a las violencias y veleidades del capital; a tal grado, que si "sopla en la China algo se suspende o redefine en nuestra fértil provincia". El asunto es que, como quiera que sea, como quiera que se articule hoy, el mismo deseo de la mercancía global, el mismo deseo de oriente (comerciar con la China), que impulsó la emergencia del reino de Chile en la primera globalización, vuelve y nos atraviesa en su fase tercera, hipertecnológica-capitalista. En la perspectiva de esta "nueva extremadura", en la que globalización y violencia -tal como en el siglo XVI- nos vuelven marcar un derrotero, una nueva condición de borde, un estado de Frontera, es que propongo una reflexión sobre el Barroco y el Neobarroco en Chile.

Quizá debemos comenzar diciendo que ningún otro territorio americano se incorpora al "Orbe del nuevo real" a través de una escritura de la violencia tan extremada como el Reino de Chile. Y añadir inmediatamente que la materia poética de esa escritura corresponde a la frontera bélica, política y simbólica más austral e inestable del avance globalizador del siglo XVI, la Frontera de Arauco. La consideración de lo uno y lo otro es literariamente importante, por cuanto en este borde fronterizo, llamado Nueva Extremadura, se produjo muy tempranamente una de las mayores y más radicales obras 
del desengaño histórico del Barroco hispanoamericano, y el primer poema anti-épico, anti-utópico, de barroquismo basal y de modernidad absoluta del Barroco indiano, La Araucana, de Alonso de Ercilla.

El asunto de este poema es la historia en su pura condición de guerra, o el exceso (moderno) nunca antes visto de la guerra en la historia: el nuevo horizonte de aniquilación en el que la guerra sin medida, sin marco legal, ni moral, ni teológico, refunda la historia como Historia Universal ${ }^{36}$. En la misma medida, es la acción devastadora de lo humano que tal condición apareja, manifiesta en la imposibilidad total de dos elementos que hasta entonces le eran constitutivos: el amor ${ }^{37}$ y la poesía. La convergencia de lo uno y lo otro en el poema señala la emergencia de una nueva dimensión de lo insignificable en el orden de la cultura y el espíritu: lo que la violencia tornó ilegible en el mundo y en el ser humano; y un nuevo insignificable poético: lo que la poesía atestigua (ve acontecer) en la historia, pero que su palabra nunca podrá comunicar. En definitiva, aquello que, de un momento a otro, la poesía atestigua como silencio. La doble dimensión de lo insignificable hace de La Araucana el primer poema americano moderno en el que se manifiesta el acontecimiento del "sublime horroroso" $38 \mathrm{y}$, en consecuencia, el primero

36 El debut de nuevas formas de extinguir masivamente al otro, por ejemplo. La imagen brutal del nuevo fruto de la muerte: "Por falta de verdugo que no había,/quien el oficio hubiese acostumbrado,/quedó casi por uso de aquel día/un método de matar jamás usado:/que a cada indio de aquella compañía/un bastante cordel le fue entregado,/diciéndole que el árbol eligiese,/ donde a su voluntad se suspendiese (...) y los robustos robles desta prueba/llevaron aquel año fruta nueva" (168). Décadas después, en el siglo XVII, la escena de numerosos cuerpos colgados de los árboles configura el motivo de uno de los grabados de la serie Las miserias de la guerra de Jacques Callot, realizada a propósito de la Guerra de los Treinta Años. A estos grabados aludió Serge Gruzinki en su conferencia titulada, significativamente, "La Guerra de Treinta Años en América y en África: la verdadera Primera Guerra Mundial", pronunciada el 24 de noviembre de 2014 en la Sala Ercilla de la Biblioteca Nacional de Chile. También remito la imagen de Ercilla a la canción de Billie Holiday Strange Fruit. Por su parte, Javier Bello alude a esta canción en un poema de Los grandes relatos. Advierto que en La Araucana se obliga al vencido a la autoaniquilación.

37 La negación rotunda de la posibilidad del amor es la primera frase del poema: "No las damas, amor, no gentilezas/ de caballeros canto enamorados; ni las muestras, regalos y ternezas/ de amorosos afectos y cuidados...". De inmediato se anuncia el asunto del poema: la guerra, el "duro yugo por la espada" (19).

38 Lo que no puede ser significado, que transmuta, incluso, la condición de la naturaleza en un nuevo "paisaje del horror": “...las muertes, el rigor y la crüeza,/esto no puede ser significado,/que la espesa y menuda yerba verde/en sangre convertida el color pierde" (47). 
que concibe la historia como holocausto. Esto es, la historia deshabitada de lo humano, regida exclusivamente por el interés político-económico, e impulsada por la violencia. El holocausto también es lo humano sin habitación en la historia.

En tanto el poema establece que la guerra es la superficie de inscripción del nuevo real, deja en claro que la violencia es el eje fundacional del "nuevo mundo global" y de Chile, como su metonimia. Asimismo, devela la correspondencia entre esa violencia y la condición de ruina genésica de la modernidad. La Araucana expone, en definitiva, la emergencia de la novedad arruinada que nos es hoy tan próxima, en cuya formación reconocemos una serie de elementos también cercanos a nuestra sensibilidad: el derrumbe de todas las utopías de la época, el pacto político del nuevo real con el $\mathrm{Mal}^{39}$ y su tácito acuerdo con la in-trascendencia de cualquier proyecto de mundo que no fuera el de la dominación de la expansión europea ${ }^{40}$.

En términos literarios, con un realismo y una crueldad que pueden ser apabullantes (incluso hoy), el poema afirma la imposibilidad de la épica en el mundo moderno, la transformación del héroe en antihéroe y de la voz poética en conciencia angustiada ante la historia. Pero donde el poema es más próximo a nuestra sensibilidad literaria es en el despunte en él de la condición

39 La escena del empalamiento de Caupolicán recién bautizado, comunicada por el poeta al monarca, ejemplifica bien ese acuerdo. La violencia (fálica en todos sus aspectos) de la penetración física y simbólica es digna de notar: el palo por el ano, las flechas en el pecho para que salga el espíritu por las heridas, la maldad de los arqueros. "No el aguzado palo penetrante,/por más que las entrañas le rompiese/barrenándole el cuerpo, fue bastante/a que al dolor intenso se rindiese..." "En esto, seis flecheros señalados,/que prevenidos para aquello estaban,/treinta pasos de trecho desviados/por orden y de espacio le tiraban;/y, aunque en toda maldad ejercitados..." “...y en breve, sin dejar parte vacía,/de cien flechas quedó pasado el pecho,/por do aquél grande espíritu echó fuera,/que por menos heridas no cupiera” (212-13). No sobra recordar que La Araucana fue un poema muy leído en su época, de tal manera que la violencia que exhibe fue ampliamente conocida en el centro emisor de la violencia.

$40 \quad$ Protagonizando el avance de la guerra de la monarquía española hacia el Estrecho de Magallanes y el avance histórico del Mal a regiones no hispanizadas, así relata Ercilla su llegada a donde no ha llegado ningún europeo, a Chiloé. "La sincera bondad y la caricia/ de la sencilla gente de estas tierras/ daban bien a entender que la codicia/ aun no había penetrado aquellas sierras; / ni la maldad, el robo y la injusticia/ (alimento ordinario de las guerras)/ entrada en esta parte habían hallado/ ni la ley natural inficionado. Pero luego nosotros, destruyendo/ todo lo que tocamos de pasada/ con la osada insolencia el paso abriendo/ les dimos lugar ancho y ancha entrada; y la antigua costumbre corrompiendo,/ de los nuevos insultos estragada,/ plantó aquí la codicia su estandarte/ con más seguridad que en otra parte” (220). 
de ruina con que se anuncia la llegada de la poesía moderna. Esto es, por un lado, la constatación de la incapacidad de la palabra poética para comunicar la conciencia humana con el mundo; $y$, más exactamente, su incapacidad de comunicar la conciencia desolada con la asolación del mundo que esa misma conciencia protagoniza ${ }^{41}$. Por otro lado, es la aparición de la poesía que ya no habla el mundo sino -autorreferencialmente- de su propia incapacidad de significar. En este sentido, la donación más importante de La Araucana a la modernidad es la anticipación del silencio poético como única posibilidad del Ser frente a la catástrofe histórica: Dejar el canto, tomar el lloro, guardar silencio $^{42}$, porque se comprende la secreta comunicación entre el exceso de la muerte y el avance de una razón que se asume e impone hegemónicamente como esencia civilizadora. También porque se comprende que ninguna noción conocida (o por inventar) de historia puede explicar ese exceso, y por lo tanto se observa que la demasía horrorosa descarrila el devenir sucesivo de lo que antes sí transcurría en y por la historia. En La Araucana se encuentra la experiencia de la falla a la que hice referencia más atrás y se muestra con claridad la relación de esa falla con el Barroco americano y la historia. Pues si bien el poema indica un hiato insalvable tanto para los cristianosespañoles como para los araucanos-mapuche, de inmediato se constituye en fuente primera para (casi todas) las obras de historia del periodo: en matriz histórica. También en matriz poética cargada de futuridad, en cuanto hace del Barroco fronterizo del Reino de Chile la modernidad antecedente del Neobarroco chileno de los años 70 en adelante.

En otro poema magnífico, La Guerra de Chile, sin fecha y anónimo, pero escrito hacia el siglo XVII, cristaliza la matriz poética-histórica del Barroco chileno de Frontera: la guerra. Pero más que la guerra, el conflicto político, que la intensidad de la beligerancia transformó en estructura fundacional del nuevo reino, y a la violencia del dispositivo rearticulador de la conciencia (de "los naturales", de los conquistadores, de los indianos, de los esclavos, de todos) al nuevo real. También matriz que se configura en el presente de la escriturade La Guerra de Chile como cita, intertexto, reescritura, versión y devoración de otro poema, de La Araucana. De tal manera que la exacta

“...pluma no basta, lengua no hay que pueda/figurar el furor con que venían..."

42 "Quiero mudar en lloro amargo el canto/que será a la sazón más conveniente,/pues me suena en la oreja el triste llanto..." (50). La crisis de la conciencia se encuentra desde la primera parte y hasta el cierre del poema: "razón que llore y que no cante" (229). 
equivalencia entre guerra y conflicto político, es el elemento apropiado, reescrito, reinscrito como matriz poética del Barroco fronterizo, la que adquirirá condición transhistórica al proyectarse, como dije, sobre el Neobarroco chileno. Por supuesto que esa matriz se constituye como escritura de la violencia. En La Guerra de Chile, el Barroco de Frontera incrementa notablemente la tensión en el lenguaje, pues si de un lado el despliegue metafórico alcanza todo el lujo de la madurez barroca, de otro, el lujo lingüístico que permite la descripción de la violencia devela su propio estrangulamiento, su casi el silencio. Si La Araucana presenta el horror como aquello insignificable por el lenguaje, en La Guerra la voz lírica hace un nuevo pacto en el orden de la significación: de la poesía con el horror para poder decir lo que el horror es. El nuevo pacto poético del Barroco de Frontera deroga, por insuficientes, a las tradicionales musas y solicita el concurso de las "negras Furias de horror tintas", para acceder a las palabras (a las "formas distintas", nuevas) que permitan nombrar lo "indecible horroroso" en tanto indecible de la historia ${ }^{43}$. El Neobarroco chileno del periodo de la dictadura también conoce de la violencia como dispositivo rearticulador de la conciencia al régimen de un nuevo real y, por lo tanto, sabe de la necesidad de ir "más allá" del silencio, en búsqueda de una (nueva) forma que permita decir, por ejemplo Lumpérica (1983) de Diamela Eltit ${ }^{44}$.

Ciertamente se pueden atraer muchas obras si lo que se quiere es abordar el Neobarroco chileno desde una perspectiva transhistórica, pues se trata de uno de los fenómenos más interesantes de la cultura y la literatura chilenas desde el siglo XVI hasta hoy, sin embargo, aquí limito el comentario a unas cuantas de ellas y solamente a algunos de los temas que he venido desarrollando. En razón de aquello, creo importante comenzar por una de las novelas más descollantes del Neobarroco latinoamericano, en la que la reescritura de la

43 "Ya con eceso mísero y violento/en el barato caro de las vidas,/hay lástima, hay sangre, hay perdimiento/hay fines, hay destrozos, hay heridas/hay güesos como polvo por el viento,/hay armas rotas y ánimas perdidas,/hay miembros sin sus cuerpos en retazos/y hay cuerpos divididos en pedazos. (...) ¿Quién bastará a sacar formas distintas/de un tan revuelto caos de desatino?,/pues mal sin luz se pueden ver las tintas, /y no hay quien yendo a ciegas lleve tino;/vosotras, negras Furias de horror tintas,/dadme para que diga algún camino/de lo que la crueldad anatomista/ no puede - por ser tanto- coronista" (261).

44 También: El Primer Libro (1985) de Soledad Fariña; La Tirana (1983) y Los Sea Harrier (1986-1993) de Diego Maquieira; entre muchos otros. 
matriz colonial articula el sentido del mundo: El obsceno pájaro de la noche (1970), de José Donoso.

Parto señalando que, desde el plano de la ciudad que se describe, hasta los ritos fúnebres con que comienza la obra, pertenecen a la cultura colonial barroca contrarreformista del Reino de Chile ${ }^{45}$. Es decir, desde el asentamiento de la ciudad (Santiago dividido por el río Mapocho; la Chimba), hasta los imaginarios del poder, de la muerte y del más allá que despliega, corresponden a ese primer momento en que la violencia inscribe a Chile como "Nueva Extremadura" y lo asienta en la historia como una Capitanía dependiente en la lejanía del Virreinato del Perú. Con esto quiero afirmar que la Colonia es el cronotopo imbunchado en el interior del mundo republicano de El obsceno pájaro de la noche, tanto como sus operaciones de lenguaje y su laberíntica proliferación de significantes (lenguaje que reproduce lenguaje, lenguaje que reproduce la falla), tienen su origen en la "productividad pura" 46 , en la "insondable eternidad" (360) del dicen que dicen de la conseja colonial ${ }^{47}$. Esto es, la historia y el mundo como acontecimientos simultáneos, aleatorios, de habla: del real desfalcado del habla.

Los espacios físicos, la "Casa de Ejercicios Espirituales de la Encarnación de la Chimba" (cuyo nombre no es otra cosa que una cita al Barroco jesuítico instalado en Chile desde 1592-93 entre las clases mestizas y criollas del poder colonial) y el fundo la "Rinconada", también son espacios económicos, políticos

45 La forma de morir y el imaginario de la muerte a los que estamos tan acostumbrados que parecen perderse en illo tempore, son, en verdad, fenómenos muy recientes en el territorio chileno, y bastante tardíos en el desarrollo de la creencia judeocristiana (1540). El "estilo barroco de la muerte" o la nueva forma de imaginar la propia ausencia del mundo, con que abre El obsceno pájaro de la noche, la podemos documentar en la Escritura Testamentaria más o menos desde 1580 en adelante.

46 Esta "productividad pura" del lenguaje proveniente del Barroco fronterizo de la Colonia chilena, también es puesta en escena por Raúl Ruiz en la serie de televisión $L a$ Recta Provincia (2007). Tanto en la novela de Donoso como en la serie de Ruiz se subraya la "performatividad oscura del lenguaje" y la relación de la palabra con el Mal, producto de sus relaciones enrarecidas con el poder trascendente y el poder terreno. La "productividad pura" del lenguaje es un rasgo general de la obra de estos dos creadores chilenos y en ambos proviene del campo ancestral chileno, en donde persisten hasta hoy con igual fuerza el "Canto a lo Divino" y la creencia en los hechizos de los brujos: "actos de lenguaje" o sustratos operantes del lenguaje son aún el Chile neoliberal.

47 "Esta conseja, difundida por todo el país, es originaria de las tierras del sur del Maule, donde los Azcoitía han poseído sus fundos desde el coloniaje" (44). "Dicen... dicen... dicen: palabra omnipotente..." (135). 
y espirituales ${ }^{48}$ coloniales sobre los que se refunda la modernidad arruinada republicana chilena ${ }^{49}$, el poder que la sostiene. De la Casa de la Chimba al fundo van y vienen el Mal y lo monstruoso, no como categorías metafísicas, ni siquiera espirituales, sino como fenómenos políticos e históricos, identificables y fechables, desde la Conquista hasta el Chile de hoy, en que continúa vigente el pacto indisoluble entre el poder eclesiástico y el político-económico ${ }^{50}$. El sostén de todo esto es otra institución colonial-barroca que regula la economía de la salvación, liga las almas de los vivos con las almas de los muertos y el poder en la tierra con las fuerzas del más allá: la Capellanía ${ }^{51}$, esa invención católica inscrita en lo material que -mediando bienes y dineros- ritualiza y eterniza la voluntad y la presencia de los poderosos para siempre jamás en la historia ${ }^{52}$ (de Chile). En términos concretos, sacraliza "la lealtad de la familia [de los poderosos] con la iglesia" (49) y de la iglesia con esa familia. El asunto, tal como lo señala el mismo narrador de la obra, es que "Todo esto

48 La unidad política, económica y espiritual de la hacienda o el fundo en Chile, desde la conquista hasta hoy.

49 La república se funda sobre la ruina colonial, de igual manera que la Colonia se funda sobre la ruina prehispánica, Ahora bien, en la modernidad acumulativa y por lo tanto mugrienta del desecho se encierran dos elementos fundamentales. En la obra, el objeto o el fragmento del objeto que carga con su materialidad espurrea la economía de la conciencia, tal como sucede en la escritura testamentaria colonial. Insisto, la colección incompleta que denuncia el absurdo en la idea del tiempo moderno y el desvanecimiento de su densidad histórica. "Lo que más mandan son camiones con desechos, santos quebrados que no se pueden tirar a la basura porque son objetos de culto y hay que respetarlos, montones de revistas y diarios viejos que van poblando habitaciones y habitaciones con sus noticias de urgencia desvanecida transformada en alimento de ratones, completando mi biblioteca de enciclopedias truncas... camionadas de objetos inconexos, relojes que no funcionan... que va llenando piezas y piezas que nunca terminan de llenarse" (55).

50 "Sin embargo, al testar, o en el lecho de muerte, ningún Azcoitía deja de poner en claro el traspaso de la propiedad de esta Casa, entre sus cuantiosos bienes, a su heredero, recordando así, finalmente, lo que en realidad nunca olvidaron: que esta capellanía sepultada en archivos, preocupación de tías beatas y primas pobretonas, vincula y emparienta desde hace mucho tiempo a los Azcoitía con Dios, y que ellos le ceden la Casa, a cambio de que Él les conserve sus privilegios", aun en la patria que ellos, desde la guerras de Independencia hasta del mundo contemporáneo, han creado (49-51).

51 La permanencia de la Capellanía desde la Colonia hasta los años 60 está documentada en el importante libro de María Eugenia Horvitz, Memoria del nombre y salvación eterna. Los notables y las capellanías de misas en Chile (1557-1930).

52 "Desde el púlpito y el confesionario, frailes de pico de oro, exhortaban a la penitencia, a la magnanimidad y al arrepentimiento, inflamando vocaciones cuya luz, a veces iluminaba la Historia" (53). 
es histórico" (355). Existió un "hecho real" (361) pero irrecuperable, que, desde la primera frontera hispano-mapuche (el primer espacio de ambiguación de los mundos en guerra, el Maule: culturalmente, el mestizaje) intervino y alteró las fuerzas espirituales de la Capellanía para fusionar en su interior el bien y el Mal, el poder terreno y la trascendencia. Ese hecho irrecuperable, borrado, oculto y encarcelado a la vez, también es lo que da lugar a una realidad monstruosa, sin origen, laberíntica, de variantes infinitas, regida por fuerzas femeninas, que traspasó de la Colonia a la República y comunica secretamente la violencia de los siglos pasados con la violencia contemporánea en Chile. En este sentido, El obsceno pájaro de la noche señala obsesivamente que la Colonia es la ruina tapiada y transparente que se reproduce hacia adentro -como el lenguaje- incesantemente al interior de la República, del mismo modo que el Barroco fronterizo es el residuo transparente y operante que se reproduce incesantemente al interior del Neobarroco actual.

En 1970 se publica El obsceno pájaro de la noche: hacia el final de la década, no solo se ha producido en Chile el violentísimo Golpe Militar liderado por el ejército y apoyado por la CIA, además, Chile se ha convertido en el laboratorio de la nueva era del capitalismo que está por despegar a nivel global. En este contexto, una de las obras barrococontemporáneas ${ }^{53}$ que captura (y es capturada) de manera más exacta la violencia política económica y el aceleramiento global de la historia de Chile, es la de Rodrigo Lira. Por lo mismo, es una de las obras neobarrocas escritas entre los finales de los 70 y comienzos de 80 que exhibe mayor grado de violencia en la sintaxis, a tal punto, que llega peligrosamente cerca al caos de la ilegibilidad.

Para referirme a su trabajo, antes debemos introducir otro elemento del Barroco de Frontera de los siglos XVI y XVII, ya reactualizados obsesivamente en El obsceno pájaro de la noche, pero, pocos años después, caracterizarán la obra de Lira tanto como la conciencia del sujeto que esta obra expone: el espacio cerrado-clausurado, el cautiverio-encarcelamiento. Por supuesto, la referencia aquí es el Cautiverio Feliz, pero también todo (escritura, historia, imaginario) lo que dice relación con la figura del cautivo o de la cautiva en la Frontera de la Guerra de Arauco: todo aquel Segismundo a quien el conflicto político ha secuestrado o le ha secuestrado su realidad.

53 Este es el término que acuña el mismo Lira en el poema "A propósito de una solicitación" (32). 
Lira es de lo primeros en establecer que después del golpe e instalación del neoliberalismo ya no se puede leer en Chile un poema como una unidad, porque la unidad no existe (no puede existir) en una cultura cautiva, de laboratorio, confinada en condiciones de borde. En tales condiciones tampoco existe nada semejante a una unidad de la poesía chilena, en cuanto esa poesía dejó, súbitamente, de ser un sistema significativo y significante de la historia y del mundo. Solo quedan poemas como restos de algo que naufragó o como restos de construcciones en una ciudad que ha sido bombardeada. Restos, sin embargo, que se pueden ocupar, en el mismo sentido y voluntad política en que, de los 60 en adelante, se okupa una casa abandonada ${ }^{54}$. Eso es lo que hace Lira, entre otros, con el poema "Gato negro a la vista" de Gonzalo Rojas. Sílaba a sílaba (como si el poema fuera una suerte de madriguera insondable), lo okupa para habitarlo con una escritura (la propia) y una sintaxis casi ilegibles, pero capaces de reinstalar el sentido, de la historia, del mundo, o de su pérdida. Lira parece titular esa ocupación y encriptación de la siguiente manera: "dQ.mentos del/ anteayer Q.atro/ gatos./ s.” (89).

Ciertamente, son muchos los temas a comentar sobre el "barroco furioso" de Lira (la relación entre el tiempo y el documento, por ejemplo), sin embargo, en este momento me interesa focalizar un fragmento mínimo de "dQ.mentos del/ anteayer Q.atro/ gatos./ s.”, en el cual la mirada transhistórica fusiona la primera globalización con la que se está experimentando (en las distintas acepciones de esta palabra) en el primer momento del laboratorio neoliberal chileno; en la emergencia de su nuevo real:

c/stituye y c/forma

una Bolsa de Gatos, enmarK.da en un sisT.ma $\mathrm{eC}^{\mathrm{o}}$ nómiC $\mathrm{C}^{\mathrm{o}}$ social de MerKa.do \& libre ${ }^{\mathrm{C}} / \mathrm{Q}$.rrenCIA

los Q.atro

(¡qué oQ.rrencias tan obsQ.ras!)

gatos

$\mathrm{S}$

son especies de la especie de las que iba a

buscar donde unas tales

Indias un señor $\mathrm{C}^{\circ}$ lón, valoradas hipotecables y reajustables

De aQ.erdo con laK.ntidad de re al $^{\text {za en las tasas de K }}$ baja o

fe o los enK.jes de (97)

$54 \quad$ La referencia aquí es el Movimiento Okupa de los años 60. 
Una globalización calza en la otra, en tanto "son especies de la especie", pues pareciera que, para reglobalizarse, la mercancía y el capital tuvieran que regresar a nutrirse en su origen, America Latina, Chile esta vez.

¿Nutrirse de qué? De oro, plata, pedrería, incluso de oro falso, pero sobre todo, de violencia. Violencia aurificada, que los metales y las piedras preciosas americanos inscribieron en clave barroca global. Si estamos diciendo esto es porque hemos llegado a Cipango ${ }^{55}$, de Thomas Harris, publicado en 1992, misma fecha, como todos sabemos, en que el mundo hispánico-católico celebraba los 500 años del viaje de Colón hacia oriente (la China, Japón, etc.): Cipángo-Las Indias.

Los libros que componen Cipango fueron escritos en la década de los ochenta, en pleno apogeo de la instalación neoliberal en Chile. Pero, no obstante la contemporaneidad de los hechos que presenta, en ellos la violencia de la dictadura reescribe la violencia de la Conquista, tanto como la violencia de la Conquista ya escribió la violencia dictatorial de la voraz instalación neoliberal: de la mercancía, del capital. En Cipango "La Guerra de Chile" pierde los bordes temporales y adquiere la dimensión de un presente absoluto, de un hecho total ${ }^{56}$, que vuelve a ocupar la historia, para presentar nuevamente la Historia en su pura condición de guerra. De tal manera que, en la misma Frontera en que se inició la Guerra de Arauco, en la ciudad de "La Concepción de María Purísima del Nuevo Extremo", en la calle Orompello, en una habitación del Hotel King, en esta angosta faja de barro, "de sangre", "de semen" $(42)^{57}$, en esta "larga y angosta faja de muerte", "lo mismo ayer hoy mañana", un tirano y el horror que inventa el horror, "el horror te inventa", nos "inventa una cárcel" (49).

El asunto del Neobarroco de Cipango (y en general el de los 80) es que reescribe el Barroco de Frontera, y lo reescribe porque la historia reescribe el horror fundacional en el presente. Porque "La Historia termina en los baldíos", "Sin forma humana" (62), tal como anuncia en el siglo XVI La Araucana.

55 En Cipango se reúnen los cuatro primeros libros de Harris. La vida a veces toma la forma de los muros, 1983; Zonas de peligro, 1985; Diario de navegación, 1986; El último viaje, 1987, más la obra que corresponde a Cipango, 1992.

56 "sus gruñidos estremecían el supermarket,/ la ciudad, el valle miserable de Concepción,/ el Universo..." (92).

57 La "faja" de barro, sangre, semen, etc., es una de las muchas citas de La Araucana. Puntualmente, es la forma geográfica que Ercilla da a Chile en su poema. 
Ahora bien, me parece que no puedo terminar este trabajo sin una mínima mención al Neobarroco "más actual", como lo denomina Kozer. Este es, el Neobarroco que se desarrolla durante el (oscuro) esplendor de la economía neoliberal, cuando Chile deja de ser un laboratorio social en condiciones de borde y se convierte en el modelo "económico-democrático" para el mundo y en exportador de productos neoliberales (AFP, ISAPRE, retail). En este Neobarroco, como dice Kozer, "más violento", se encuentra una amplia referencia, cita o reescritura de La Araucana; es decir, una vasta presencia de la matriz poética transhistórica del Barroco chileno: el conflicto político, la guerra y la violencia como dispositivo articulador de la conciencia a lo real ("yo batalla yo derrota"). En este sentido, me interesa focalizar un fragmento del poema "Pero estas palabras fueron la traducción" de Héctor Hernández ${ }^{58}$, y remitir a una relectura del poema de Ercilla y a una lectura transhistórica del Barroco de Frontera en Chile:
Desde acá Desde mi Paccha Mamma nada pueden hacer los que contra mi cerviz seis ojos tuvieron Esos que maldijeron diciendo mal Los que perdieron piernas por espadas Los que dijeron yo batalla yo derrota Los que derribaron amigos gentilicios genitales gentiles

\section{BIBLIOGRAFÍA}

Carpentier, Alejo. "Lo Barroco y lo Real Maravilloso". Razón de ser. La Habana: Ed. Letras Cubanas, 1984.

Carrillo, Rubén. “Asia llega a América. Migración e influencia cultural asiática en Nueva España (1565 -1815)". Asiadémica (Revista Universitaria de Estudios sobre Asia Oriental), enero 2014: 81-98.https://dl.dropboxusercontent.com/u/6359676/Asiademica/03/ Asiademica03_07_Carrillo.pdf

Colón, Cristóbal. Textos y documentos completos. Relaciones de viajes, cartas y memoriales.

Ed. Consuelo Varela. Madrid: Alianza, 1982.

De la Cruz, Sor Juana Inés. Obras completas. México: Porrúa, 1989.

Díaz del Castillo, Bernal. Historia verdadera de la conquista de la Nueva España. México: Porrúa, 1970.

58 Cabe destacar que este poema fue antologado en el libro Desencanto personal: Reescritura del Canto General de Pablo Neruda. 
Donoso, José. El obsceno pájaro de la noche. Santiago: Alfaguara, 1997

Ercilla y Zúñiga, Alonso de. La Araucana. Santiago: Editorial del Pacífico, 1956.

Egido, Teófanes, coord. Los jesuitas en España y el Mundo Hispánico. Madrid: Marcial PonsFundación Carolina Centro de Estudios Hispánicos e Iberoamericanos, 2004.

Gruzinski, Serge. Las cuatro partes del mundo: Historia de una mundialización. México: Fondo de Cultura Económica, 2010.

Harris, Tomás. Cipango. Santiago: Fondo de Cultura Económica, 1996.

Hausser, Arnold. Manierismo. La crisis del renacimiento y lo orígenes del arte moderno. Madrid: Guadarrama, 1969.

Hernández Montecinos, Héctor. El barro lírico de los mundos interiores más oscuros que la luz. Santiago: Contrabando del bando en contra, 2003.

Hernández, Héctor, Víctor López, Rodrigo Olavarría et al. Desencanto personal: Reescritura del Canto General de Pablo Neruda. Santiago: Cuarto Propio, 2004.

Horvitz, María Eugenia. Memoria del nombre y salvación eterna. Los notables y las capellanías de misas en Chile (1557-1930). Santiago: Departamento de Ciencias Históricas, Universidad de Chile, 2006.

Indios del espíritu: Muestra de poesía del Cono Sur. Comp. y pról. Roberto Echavarren. Buenos Aires: La Flauta Mágica, 2013.

La Guerra de Chile. Ed. Mario Ferreccio Podestá y Raïsa Kordic Riquelme. Santiago: Biblioteca Antigua Chilena (4), Departamento de Ciencias Históricas, Seminario de Filología Hispánica, Universidad de Chile, 1996.

Lezama Lima, José. La Materia Artizada (Críticas de Arte). Comp. José Prats Sariol. Madrid: Tecnos, 1996.

Lira, Rodrigo. Proyecto de obras completas. Santiago: Universitaria, 2004.

Mann, Charles C. 1493: Una nueva historia del mundo después de Colón. Trad. Stella Mastrángelo. Buenos Aires: Capital intelectual/Katz, 2013.

Manrique, Jorge Alberto. Una visión del arte y de la historia. Tomo III. México: Universidad Nacional Autónoma de México, Instituto de Investigaciones Estéticas, 2001.

Oviedo, Gonzalo Fernández de. Sumario de la natural historia de las indias. Ed. Nicolás del Castillo Mathieu. Bogotá: Instituto Caro y Cuervo-Universidad de Bogotá Jorge Tadeo Lozano, 1995.

Pascal, Blaise. Pensamientos. Trad. Eugenio d'Ors. Buenos Aires: Losada, 2003.

Pineda y Bascuñán, Francisco Núñez de. Cautiverio Feliz. Edición crítica de Mario Ferreccio Podestá y Raïssa Kordic Riquelme. Santiago: Biblioteca Antigua Chilena (5), Facultad de Filosofía y Humanidades, Universidad de Chile y RIL, 2001.

Sigüenza y Góngora, Carlos de. "Teatro de Virtudes Políticas”. Seis obras. Ed. William G. Bryant. Caracas: Ayacucho, 1984.

Valdivia, Pedro de. Cartas de Relación de la Conquista de Chile. Ed. Mario Ferreccio Podestá. Santiago: Universitaria, 1970.

Vespucio, Américo. El nuevo mundo: cartas relativas a sus viajes y descubrimientos. Ed. Roberto Levillier. Buenos Aires: Editorial Nova, 1951. 